\title{
Tenacity-mediated selective predation by oystercatchers on intertidal limpets and its role in maintaining habitat partitioning by 'Collisella' scabra and Lottia digitalis
}

\author{
Thomas Hahn*, Mark Denny \\ Hopkins Marine Station of Stanford University, Pacific Grove, California 93950, USA
}

\begin{abstract}
Limpet homing behavior and habitat partitioning were studied near Monterey Bay (California, USA) from the standpoint of predation by oystercatchers. Lottia digitalis and 'Collisella' scabra tend to be segregated with respect to oystercatcher accessibility: L. digitalis are most abundant out of reach of oystercatchers on vertical surfaces, whereas ' $C$.' scabra predominate on horizontal surfaces and vertical rock faces within oystercatcher reach. This difference in distribution correlates well with preference exhibited by foraging oystercatchers in that ' $C$.' scabra is neglected relative to its great abundance within reach in foraging areas, while $L$. digitalis and other related limpets are preferred by hunting oystercatchers. Limpet tenacity was measured with a device which simulates oystercatcher attack (a horizontally directed peck); ' $C$.' scabra were significantly more difficult to remove by this means. Furthermore, on softer rocks (e. g. sandstone) where 'C.' scabra often torms an indented home depression in the rock surface, limpets inhabiting the deepest home depressions were the most difficult to dislodge. We propose that the homing behavior of ' $C$.' scabra confers superior resistance to oystercatcher attack through the intimate fit to the home site, thereby allowing this species to inhabit regions accessible to birds. Thus, oystercatcher predation may act as one selective force in maintaining the homing behavior of ' $C$.' scabra. L. digitalis are removed selectively by foraging oystercatchers, and consequently occur as large individuals only on vertical surfaces out of oystercatcher reach. We suggest that it is the interplay between (1) homing by ' $C$.' scabra, (2) the resultant preference shown by oystercatchers for other limpets such as $L$. digitalis, and (3) competitive interactions between $L$. digitalis and ' $C$.' scabra on vertical surfaces which produces observed patterns of habitat partitioning by these 2 limpet species in central California.
\end{abstract}

\section{INTRODUCTION}

The factors responsible for the distributions and behaviors of temperate zone rocky intertidal invertebrates have been studied extensively. Factors such as salinity and desiccation, competition among invertebrates, food preference and availability, and predation by other invertebrates have all received considerable attention and are clearly important selective pressures. Only recently has the influence of predation by vertebrates such as birds and fish been investigated (e. g. Hartwick 1981, Edwards et al. 1982, Frank 1982, Hoc-

\footnotetext{
- Addressee for correspondence; present address: Department of Zoology, NJ-15, University of Washington, Seattle, Washingon 98195 , USA
}

key et al. 1983, Marsh 1986, 1987, Lindberg et al. 1987). Birds, particularly oystercatchers, can play a significant role in structuring rocky intertidal communities (Frank 1982, Hockey et al. 1983, Marsh 1986, 1987, Lindberg et al. 1987). In California, oystercatchers may be particularly important because, unlike most other rocky intertidal shorebirds, they reside there throughout the year (Lindberg et al. 1987 and pers. obs.) and chiefly consume molluscs, concentrating on limpets and mussels (e. g. Hartwick 1976).

In this study we address 2 main aspects of limpet predation by the American black oystercatcher Haematopus bachmani. The first regards the association between oystercatcher predation and the distribution of 2 common limpets of the rocky coast of central California, 'Collisella' scabra (quotation marks at sug- 
gestion of D. R. Lindberg, pers. comm., due to taxonomic reassessment, as yet unpublished), and Lottia digitalis (formerly Collisella digitalis; limpet nomenclature in this paper follows Lindberg 1986). These 2 snails segregate spatially according to the angle of the substratum at some central California locales such as Monterey Bay and Carmel Bay (Haven 1971 and pers. obs.). ' $C$.' scabra is most abundant on horizontal and gently sloping substrata, and $L$. digitalis occurs chiefly on vertical and overhanging rock surfaces. Analyses of this distributional pattern fail to explain fully the separation of these species. Haven's results (1973) suggested competition for food between $L$. digitalis and 'C.' scabra as one possible reason for spatial separation. Although it can account for separation, competition alone cannot account for any particular pattern of limpet distribution. Haven presumed that horizontal surfaces are subject to more severe desiccation than vertical surfaces, and he proposed that the tight fit of ' $C$.' scabra to a home site provides superior protection against this stress. He concluded that ' $C$.' scabra is thus free to inhabit horizontal rocks in the high intertidal zone whereas $L$. digitalis is not. Wolcott (1973) has shown, however, that $L$. digitalis produces a mucous sheet between its shell margin and the rock surface, thereby maintaining a desiccation rate similar to that of 'C.' scabra.

We present evidence indicating that oystercatchers near Monterey, California, forage selectively for limpets, choosing species such as Lottia digitalis and $L$. pelta in preference to the much more abundant 'Collisella' scabra (see also Lindberg et al. 1987). We discuss the importance of this selectivity in maintaining the scarcity of $L$. digitalis on horizontal surfaces, and on vertical surfaces accessible to oystercatchers.

The second issue addressed in this study regards the adaptive significance of the homing behavior displayed by 'Collisella' scabra. Unlike some other 'homing' species (e. g. Lottia gigantea and L. digitalis), which may occasionally return to roughly the same position on the rock to rest during low tide (Galbraith 1965, Breen 1971), 'C.' scabra return to exactly the same spot on the rock and adopt exactly the same orientation each time the tide falls (Hewatt 1940, Brant 1950). Typically, if ' $C$.' scabra live on hard substrata such as granite they grow their shell to fit precisely the contours of their homesite. On softer substrata such as sandstone they may etch a depression into the surface of the rock (Lindberg \& Dwyer 1983). Homing is so precise that some researchers who examined the limpets only at low tide concluded that the animals never move at all (Villee \& Groody 1940).

Limpet homing in general has received considerable attention, and some studies identify adaptive functions of the behavior. Mackay \& Underwood (1977) show that homing serves to disperse evenly individual Cellana tramoserica during periods of food abundance. Wolcott (1973) found that 'Collisella' scabra was not as effective at constructing desiccation-retarding mucous sheets as Lottia digitalis, and consequently required a close fit to the substratum to keep desiccation to a tolerable level. Several studies have shown that ' $C$.' scabra which have access to a home depression are significantly less susceptible to predation by various invertebrates than are 'C.' scabra which lack a home depression (Wells 1980, Kunz \& Connor 1986). Kunz \& Connor (1986) suggest that one possible reason for the relative immunity to predation is that limpets on home depressions display greater tenacity, particularly in resistance to shear forces, than limpets lacking depressions. We tested the hypothesis that the tight fit resulting from precise homing may provide improved tenacity, and we present quantitative evidence that the home depression improves resistance of 'C.' scabra to attack by oystercatchers.

Finally, we unite the results of our investigation with those of previous studies to provide what we think is a more plausible and complete explanation of the distributional patterns of 'Collisella' scabra and Lottia digitalis. We suggest that in central California $L$. digitalis occupies primarily vertical surfaces out of reach of oystercatchers because of selective predation by these birds; 'C.' scabra is free to inhabit areas accessible to oystercatchers due to improved tenacity which results from its homing behavior, but is discouraged from occupying some vertical areas by competition with L. digitalis.

\section{METHODS}

Observation of oystercatchers. Observations of birds were made with $9 \times 35$ binoculars and a $20 \times$ telescope. The birds around the Monterey Peninsula tolerate human activity, obviating the need for blinds. These observation methods allowed positive identification of most oystercatcher prey items to general categories (primarily limpets, mussels, chitons) but usually not to species.

Study sites. Most field work was done between spring 1982 and fall 1985 along the rocky shoreline of the Monterey Peninsula (Monterey County, California, USA, $35^{\circ} 35^{\prime} \mathrm{N}, 121^{\circ} 55^{\prime} \mathrm{W}$ ), in particular in the vicinities of Hopkins Marine Station and Point Pinos (Pacific Grove) and at Stillwater Cove in Carmel Bay just south of Pacific Grove. We refer to several specific sites by number in the results: granite sites 1 and 4 are at Hopkins Marine Station, granite sites 2 and 3 at Point Pinos, and sandstone site 1 at Stillwater Cove. Some tenacity measurements were taken at Garipata Beach 


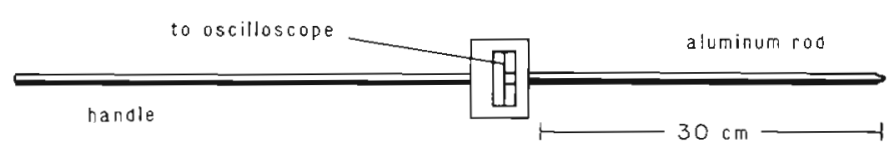

Fig. 1. (A) Device for measuring force required by an oystercatcher to dislodge limpets. The device is held like a pool cue to deliver a 'peck' to a limpet. (B) Schematic cross section of the force transducer. The stainless steel beam is $0.5 \mathrm{~mm}$ thick, $38 \mathrm{~mm}$ long, and $25 \mathrm{~mm}$ wide. Silicone rubber bushing inhibits lateral motion of the aluminum rod

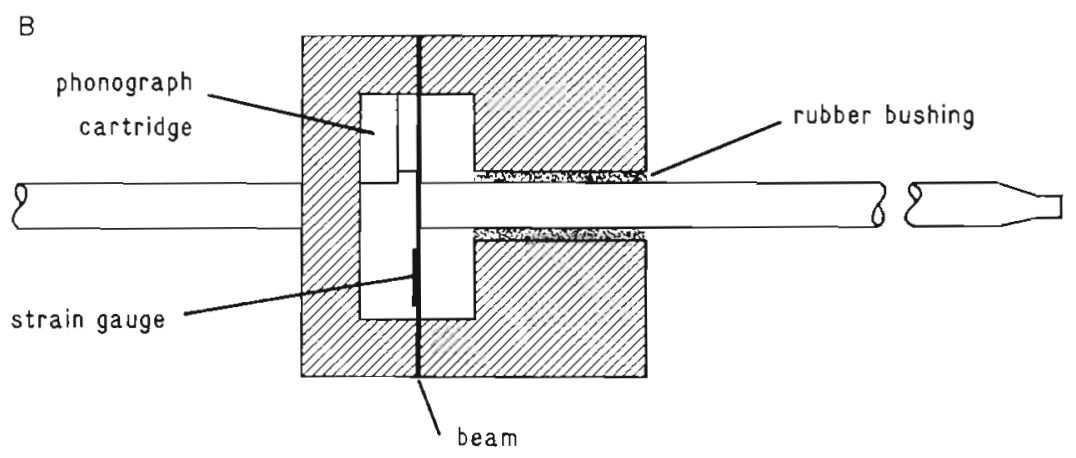

(granitic substratum), immediately to the south of Carmel Bay.

Limpet sampling. Distribution of limpets on vertical surfaces was measured by dividing vertical rock faces into $25 \mathrm{~cm}$ high horizontal bands, measured upward from the bottom where oystercatchers could walk. 'Collisella' scabra and Lottia digitalis were counted in each band, which was as wide as the rock allowed, and the numbers later converted to densities per $\mathrm{m}^{2}$ of surface sampled. Oystercatchers could reach the lowest band ( 0 to $25 \mathrm{~cm}$ above the horizontal surface on which birds could walk), could partially reach the 26 to $50 \mathrm{~cm}$ band (up to about $35 \mathrm{~cm}$ above the bottom), but could not reach the 51 to $75 \mathrm{~cm}$ band.

At sites where diet was compared with limpet availability, $0.0625 \mathrm{~m}^{2}$ quadrats were placed haphazardly and all limpets within each counted. In some instances slightly different methods were used. At granite site 1 , 'Collisella' scabra density was measured as just described, but all other species were counted in total for the entire $19.25 \mathrm{~m}^{2}$ foraging area (the horizontal top of a large granite slab) and converted to density per $\mathrm{m}^{2}$. At granite site 3, 3 parallel transects $20 \mathrm{~cm}$ wide and running the length of the foraging area were sampled instead of haphazard quadrats. We counted all limpets in each transect and converted the averages of the three to densities. Since, in most areas, species other than 'C.' scabra were very scarce in reach of oystercatchers, all other limpets are combined into one group (other) in our results.

Whenever size measurements were made, calipers with precision of $0.01 \mathrm{~mm}$ were used, and measurements made to the nearest $0.1 \mathrm{~mm}$.

Diet sampling. Oystercatchers were observed for- aging at all of the sites sampled for limpets, as well as at numerous other sites. We would search through the foraging region immediately after the oystercatchers left the area to collect as many shells of prey as we could find. The shells of limpets eaten recently by oystercatchers are readily distinguished from other shells because they are left lying about conspicuously on top of rocks and algae, usually upside down and often containing small remnants of flesh. Questionable shells were not collected.

As a measure of selectivity, we calculated an electivity index, simply the percentage of a species occurring in the diet divided by its percentage of all limpets available to the birds on the foraging area. Values of the electivity index less than 1 indicate avoidance, and values greater than 1 indicate preference.

Tenacity measurements. Tenacity (dislodgement force per foot area) of limpets was measured on undisturbed individuals in the field using a device which simulates the peck delivered by an oystercatcher (Fig. 1). The apparatus is wielded in the fashion of a pool cue with an aluminum rod serving as a replica of the oystercatcher's bill. The impact force exerted by the rod on a limpet results in the deflection of the beam to which the base of the rod is attached; the larger the force, the greater the deflection. The deflection of the beam is transduced to a voltage signal by a piezoelectric ceramic phonograph cartridge (Astatic 93 TX), and recorded on a battery-powered, storage oscilloscope (Tectronix model 214). A successful 'peck' with the apparatus results in the dislodgement of the limpet, and the recorded peak voltage (proportional to peak force) is used in the calculation of tenacity. The peak force is exerted precisely at the moment when the 
tenacity of the limpet is reached. Consequently, when a 'peck' dislodges a limpet, the peak force recorded on the oscilloscope is equal to the minimum force required to dislodge the limpet by this means.

A phonograph cartridge is used as the displacement transducer because it requires no external power supply and produces a signal of several volts, thus avoiding the need for an amplifier. In these respects the cartridge is ideal for a field-portable instrument. However, the current output from the phonograph cartridge is negligible. As a result, static deflections of the beam cannot be measured accurately using the relatively low input-impedance amplifiers of the oscilloscope, and calibration of the device must be carried out in 2 steps. A resistance strain gauge mounted on the beam serves as a mechanism for measuring static beam deflections in the laboratory. The gauge is wired as one arm in a Wheatstone bridge, and the resulting voltage signal (proportional to force) is amplified (Gould model 13 4615-30 bridge preamplifier). The aluminum rod is held vertically, known weights are applied, and the resulting voltages noted. The rod is then repeatedly tapped against a solid structure, applying a range of impact forces, and the voltage output of the phonograph cartridge is regressed against the voltage signal from the strain gauge to provide the calibration for the field-portable configuration of the device.

Only tenacity measurements from successful 'pecks' (i. e. limpet is dislodged) are included in our results. Where assumptions of normality or homogeneity of variances are not met, we use non-parametric statistical tests in the analysis of these data.

\section{RESULTS}

\section{Spatial separation of 'Collisella' scabra and Lottia digitalis}

Oystercatchers can reach about $35 \mathrm{~cm}$ up a vertical rock when standing at the base lestimated from measurements of a museum specimen and from field observation of foraging birds), and we have observed them removing Lottia digitalis from vertical rocks on numerous occasions. In our study areas $L$. digitalis are most abundant above the reach of oystercatchers (Fig. 2), and those living out of reach tend to be larger than those few living within reach (Fig. 3). In addition, on portions of vertical surface accessible to oystercatchers, 'Collisella' scabra is often the most abundant limpet, but its numbers are lower on vertical surfaces out of reach where $L$. digitalis are abundant (Fig. 2).

The distribution of 'Collisella' scabra and Lottia digitalis on vertical surfaces is not simply a zonation phenomenon based on intertidal height and physical

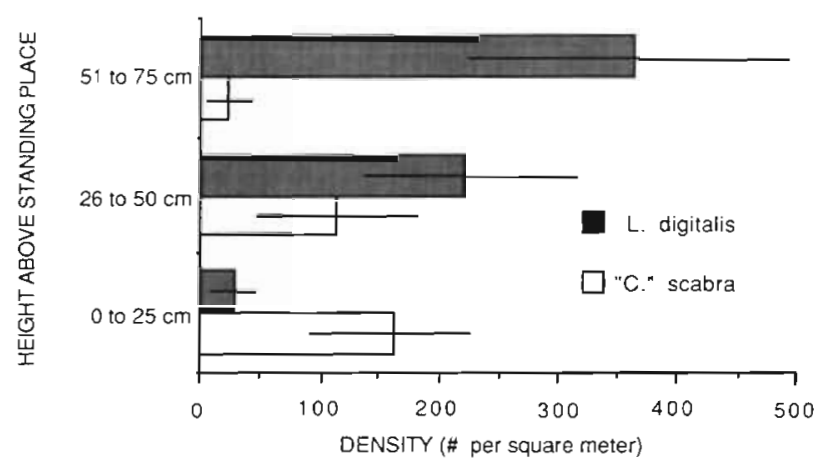

Fig. 2. 'Collisella' scabra and Lottia digitalis. Densities (ind. $\mathrm{m}^{-2}$ ) with respect to reach of oystercatchers. Heights are measured from horizontal areas on which oystercatchers could stand at the base of the vertical region, 0 to $25 \mathrm{~cm}$ is entirely within easy reach (16 sites; 'C.' scabra mean $=163, \mathrm{SD}=124$; L. digitalis mean $=28, \mathrm{SD}=36$ ); 26 to $50 \mathrm{~cm}$ is partially (up to about $35 \mathrm{~cm}$ ) in reach (16 sites; ' $C$.' scabra mean $=113, \mathrm{SD}=$ 121 i L. digitalis mean $=221, \mathrm{SD}=160) ; 51$ to $75 \mathrm{~cm}$ is entirely out of reach $(13$ sites; ' $C$.' scabra mean $=22, \mathrm{SD}=28$; L. digitalis mean $=362, \mathrm{SD}=213$ ). Error bars are intervals of $95 \%$ confidence

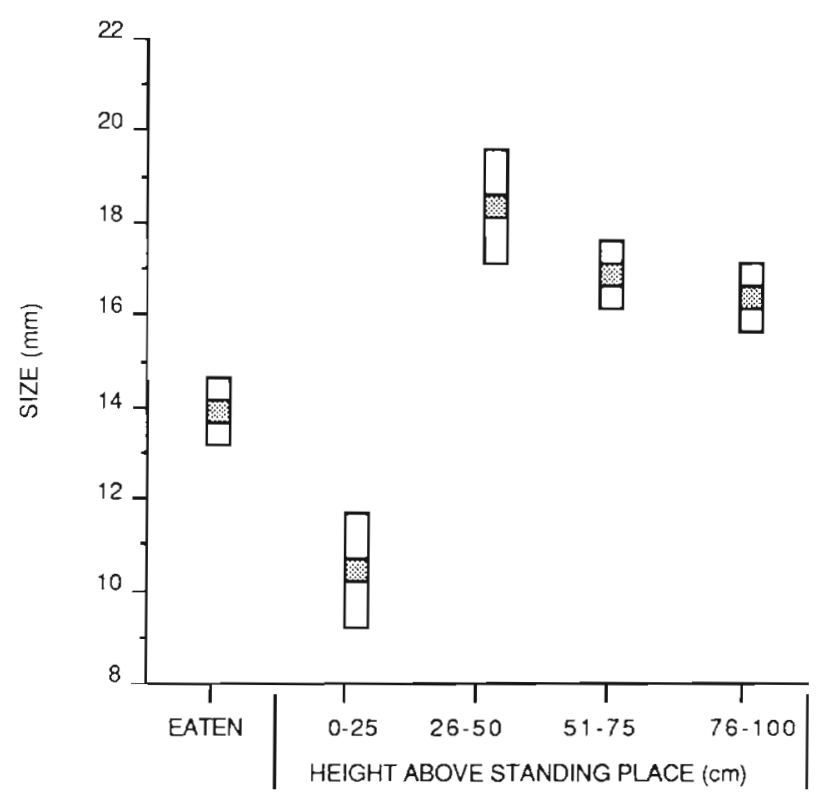

Fig. 3. Lottia digitalis. Illustration of the fact that individuals within reach of oystercatchers are smaller than those out of reach, and that oystercatchers foraging at the sites represented removed larger limpets in reach. Data presented (means, shaded box; $95 \%$ confidence intervals, open box) are from the sites illustrated in Fig. 4. Shells of L. digitalis eaten were collected in the immediate vicinity of the vertical faces sampled. Height intervals above the standing place have the same significance as in Fig. 2. Sample sizes: eaten, $n=36,0$ to $25 \mathrm{~cm}, n=19 ; 26$ to $50 \mathrm{~cm}, n=63 ; 51$ to $75 \mathrm{~cm}, n=188 ; 76$ to $100 \mathrm{~cm}, n=148$

factors. Fig. 4 shows distributions of ' $C$ ' scabra and L. digitalis at 3 areas within a few meters of one another at Point Pinos. The sites are at different intertidal heights, both absolutely and relative to biological zonation (e. $\mathrm{g}$. 


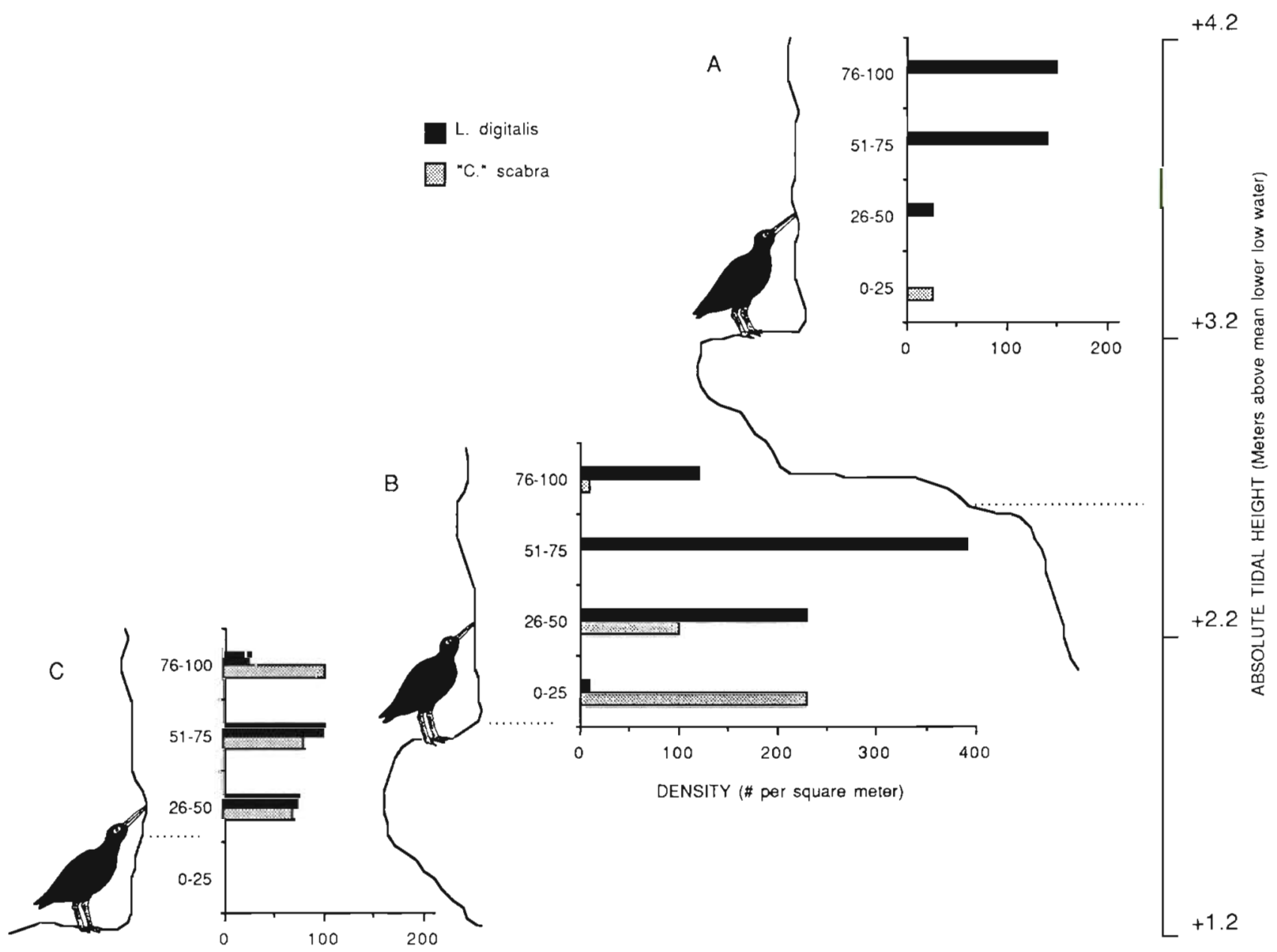

Fig. 4. Relationship between limpet density, reach of oystercatchers, and absolute and biological tidal height. Relative heights are shown to scale. The region inhabited by the alga Endocladia muricata is shown for each site as a shaded area, with a dotted line indicating its maximum height. Site $\mathrm{A}$ was the least protected from waves and site $\mathrm{C}$ the most protected. Height intervals above the standing place have the same significance as in Fig. 2

the upper limit of the alga Endocladia muricata). The absolute heights are shown to scale; the standing place in Fig. $4 \mathrm{C}$ lies at $\mathrm{ca}+1.2 \mathrm{~m}$ above mean lower low water. Although on some rocks (e. g. 4C) the 2 species coexist extensively, at all intertidal levels $L$. digitalis only become abundant out of reach of oystercatchers in this area.

\section{Selectivity of oystercatchers}

Both limpet size and species play roles in determining the likehihood that an oystercatcher will attack it, and observed selectivity correlates well with the observed distribution patterns of 'Collisella' scabra and Lottia digitalis. Throughout our study, oystercatchers seldom took limpets smaller than $10 \mathrm{~mm}$ in shell length (Fig. 5), although small limpets were generally abundant in the foraging areas. Birds foraging on sandstone and granite showed similar size preferences (Fig. 5).

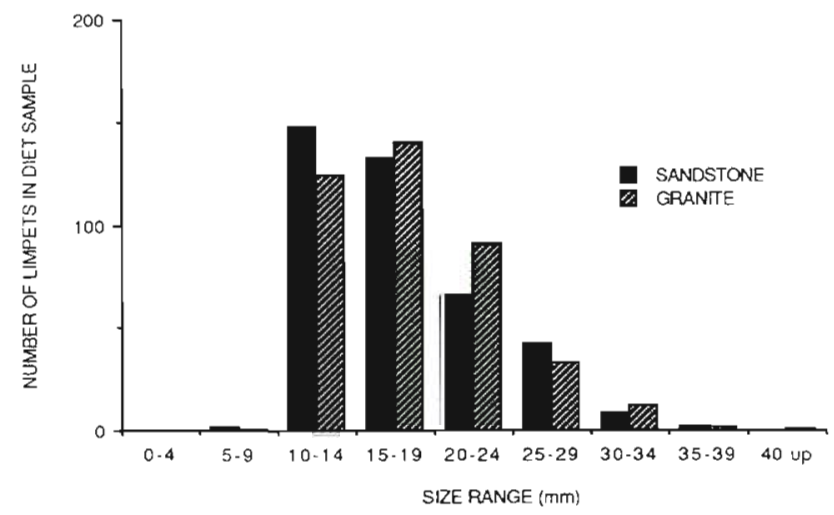

Fig. 5. Demonstration of the size selectivity of oystercatchers. Data presented are pooled from all sites on sandstone and granite

In areas accessible to oystercatchers in the high intertidal and splash zone, 'Collisella' scabra is by far the most abundant limpet, outnumbering all other 
Table 1. 'Collisella' scabra and other limpets. Comparison between limpets available and those selected by oystercatchers at 5 different sites. Availability estimates are mean densities (number per $\mathrm{m}^{2}$ ) from quadrat or transect samples taken at each site (at granite site $1\left[^{\circ}\right]$, all individuals of all species except ' $C$.' scabra were counted for the entire foraging area). SE: standard error

\begin{tabular}{|c|c|c|c|c|c|c|c|c|}
\hline \multirow[t]{2}{*}{ Site } & \multirow{2}{*}{$\begin{array}{c}\text { 'C.' scabra } \\
\text { in diet }\end{array}$} & \multirow{2}{*}{$\begin{array}{l}\text { Others } \\
\text { in diet }\end{array}$} & \multirow{2}{*}{$\begin{array}{l}\text { C.'scabra } \\
\text { available }\end{array}$} & \multirow[t]{2}{*}{$\mathrm{SE}$} & \multirow{2}{*}{$\begin{array}{c}\text { Others } \\
\text { available }\end{array}$} & \multirow[t]{2}{*}{ SE } & \multicolumn{2}{|c|}{ Electivity index } \\
\hline & & & & & & & 'C.' scabra & Others \\
\hline Granite site 1 & 2 & 23 & 115.5 & 21.0 & 26.0 & $\cdot$ & 0.1 & 5.01 \\
\hline Granite site 2 & 28 & 12 & 60.8 & 15.6 & 1.6 & 1.6 & 0.72 & 11.7 \\
\hline Granite site 3 & 9 & 2 & 67.3 & 18.9 & 2.5 & 1.8 & 0.85 & 5.08 \\
\hline Granite site 4 & 16 & 10 & 54.7 & 16.3 & 9.3 & 4.6 & 0.73 & 2.65 \\
\hline Sandstone site 1 & 19 & 5 & 168.0 & 20.0 & 16.0 & 10.9 & 0.79 & 2.4 \\
\hline
\end{tabular}

species combined in most areas. In spite of this fact, oystercatchers tend to neglect 'C.' scabra, choosing relatively rare limpets such as Lottia digitalis and L. pelta preferentially (Table 1). At some sites (e. g. granite site 1) the birds showed a striking neglect of ' $C$.' scabra, but even at sites where they ate numerous ' $C$.' scabra (all other sites in Table 1), they selected other species more frequently and 'C.' scabra less frequently than the relative abundances on the foraging sites would lead us to expect. The electivity indices for ' $C$.' scabra are all less than 1 (avoidance), and for combined other species are greater than 1 (preference; 1-tailed sign tests, both $p<0.031$ ).

\section{Tenacity and role of home site}

We find good reason for the selectivity displayed by foraging oystercatchers. There is a substantial difference between 'Collisella' scabra and Lottia digitalis in how their shells fit the rock on which they live (Fig. 6). On hard substrata such as granite (Fig. 6A), the shell margin of ' $C$.' scabra grows to match the contours of the home site precisely; no depression is formed. L. digitalis living on granite have smooth shell margins which fit the irregular rock surface poorly (Fig. 6B). On sandstone, which is smoother and softer than granite, 'C.' scabra often (but not always) forms a depression in
A

B

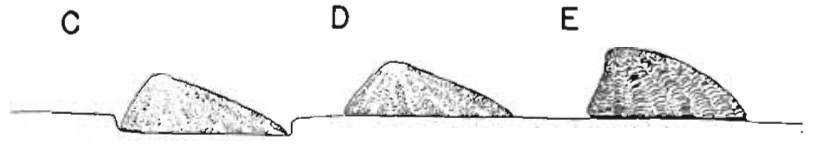

Fig. 6. 'Collisella' scabra and Lottia digitalis. Illustration of differences between fit to different substrata. (A) ' $C$.' scabra and (B) L. digitalis on rough granite. 'C.' scabra (C) in home depression and (D) without home depression on sandstone. (E) L. digitalis on sandstone. Shading beneath shell in (B) and (E) represents exposed edge of foot

the rock surface at its home site (Fig. 6C, D). L. digitalis is not known to etch or inhabit depressions on sandstone (Fig. 6E; Lindberg \& Dwyer 1983).

Clearly, the close fit of 'Collisella' scabra to rough surfaces such as granite, or the possession of a home depression on other surfaces, means that a shear force (such as the peck of an oystercatcher) applied to the limpet will not only be working against the strengh of the foot, but also against the rock which physically supports the shell. As a result, both the strength of the shell and of the rock supporting the shell probably limit 'C.' scabra's resistance to a shear force, rather than merely the tenacity of the foot. We tested tenacity for

Table 2. 'Collisella' scabra and Lottia digitalis. Summary of tenacity measurements. Mean tenacities are expressed in newtons per $\mathrm{cm}^{2}$ of foot surface. $Z$ and $p$ values are for Mann-Whitney comparisons of tenacities of the 2 species at each site

\begin{tabular}{|c|c|c|c|c|c|c|c|c|c|c|}
\hline \multicolumn{4}{|c|}{ 'C.'scabra } & \multicolumn{3}{|c|}{ L. digitalis } & \multirow[b]{2}{*}{ Substratum } & \multirow[b]{2}{*}{ Site } & \multirow[b]{2}{*}{$Z$} & \multirow[b]{2}{*}{$p$} \\
\hline $\begin{array}{l}\text { Tenacity } \\
\left(\mathrm{N} \mathrm{cm}^{-2}\right)\end{array}$ & $\mathrm{SD}$ & $n$ & $\begin{array}{l}\text { Scar } \\
\text { depth }\end{array}$ & $\begin{array}{l}\text { Tenacity } \\
\left(\mathrm{N} \mathrm{cm}^{-2}\right)\end{array}$ & $\mathrm{SD}$ & $n$ & & & & \\
\hline 144.00 & 37.10 & 12 & Deep & - & - & - & Sandstone & Stillwater Cove & - & - \\
\hline 94.00 & 39.90 & 24 & Shallow & - & - & - & Sandstone & Stillwater Cove & - & - \\
\hline 77.60 & 27.80 & 29 & Very shallow & - & - & - & Sandstone & Stillwater Cove & - & - \\
\hline 76.20 & 31.10 & 19 & None & 22.70 & 8.46 & 25 & Sandstone & Stillwater Cove & -5.34 & $<0.001$ \\
\hline 174.00 & 85.20 & 7 & None & 3.88 & 3.60 & 11 & Granite & Garipata Beach & -3.73 & $<0.001$ \\
\hline 27.80 & 24.90 & 13 & None & 2.12 & 1.88 & 8 & Granite & Point Pinos & -3.35 & $<0.001$ \\
\hline 14.40 & 2.21 & 3 & None & 2.11 & 1.65 & 29 & Granite & Hopkins & -2.78 & 0.005 \\
\hline
\end{tabular}


Table 3. 'Collisella' scabra. Results of pairwise comparisons between tenacities of limpets with scars of different depths. (Kruskall-Wallis test, Q-statistic calculated as in Zar 1984)

\begin{tabular}{|lcc|}
\hline Comparison & $Q$ & $p$ \\
\hline Deep vs shallow scar & -2.99 & $<0.02$ \\
Deep vs very shallow scar & -4.08 & $<0.001$ \\
Deep vs no scar & -4.08 & $<0.001$ \\
Shallow vs very shallow scar & -1.24 & $>0.50$ \\
Shallow vs no scar & -1.45 & $>0.50$ \\
Very shallow vs no scar & -0.35 & $>0.50$ \\
\hline
\end{tabular}

both species of limpets living on sandstone and granite (Table 2). On sandstone, different individual 'C.' scabra possess depressions of different depths, and limpets in deeper ones had greater mean tenacities (Table 3; Kruskall-Wallis test, $H=20.03, p<0.001 ; Q$-statistic calculated as in Zar 1984). Significantly more force was required to dislodge all groups of 'C.' scabra tested, including those without a depression, than to dislodge Lottia digitalis (all $p<0.005$; Table 2). Although ' $C$.' scabra living on granite do not make depressions and consequently could not be categorized according to home site quality, they do fit closely to rock irregularities (Fig. 6A) and were significantly more difficult to dislodge than L. digitalis (Table 2).

\section{Prevalence of 'Collisella' scabra with home depressions on sandstone}

As noted above, not all of the 'Collisella' scabra living on sandstone at Stillwater Cove possess home depressions of equal quality. We scored a total of 394 haphazardly selected individual limpets for possession of home depressions. In general, a greater percentage of the larger limpets possessed well-formed home depressions than did the smaller limpets (Fig. 7A). When all sizes are lumped, $180(46 \%)$ were found living on deep home depressions, and $63(16 \%)$ had no depression at all. The remainder had depressions of intermediate quality. For comparison, we plot the distribution of sizes of 'C.' scabra selected by oystercatchers foraging in the same area (Fig. 7B). Note in particular the prevalence in the diet of ' $C$.' scabra from 13 to $17 \mathrm{~mm}$ in length and the scarcity of larger individuals. The small number of large ' $C$.' scabra in the oystercatcher diet is not simply due to a low availability of large individuals. We calculated expected frequencies of each size in the diet (based on the haphazard sample of limpets just described) and obtained an index of preference by subtraction of the expected frequency from the observed frequency of each size in the diet. This index varies from negative (indicating avoidance) through zero (random choice) to positive (preference).
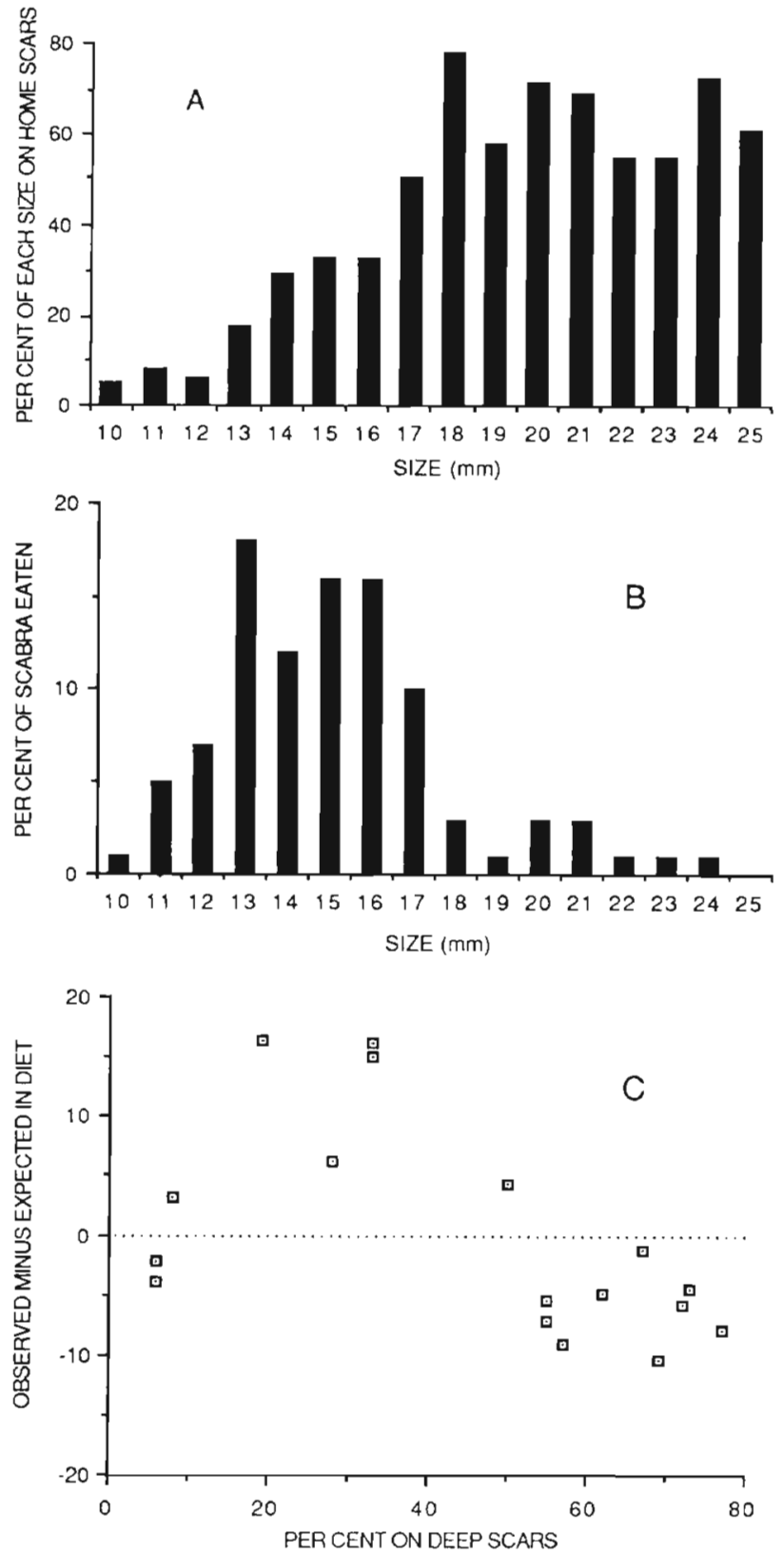

Fig. 7. 'Collisella' scabra. On sandstone at Stillwater Cove, demonstrations of (A) higher incidence of home depression occupation by larger limpets, (B) preference of oystercatchers for medium sized limpets, and (C) the fact that oystercatcher choice is biased against sizes of limpets likely to have deep home depressions. In (A), each bar expresses percentage of limpets of that size which were found living in a deep depression. In (B), each bar shows the percentage each size represents of all ' $C$.' scabra eaten in the sampling area. In (C), the $\mathrm{Y}$-axis is an index of preference, calculated by subtracting the expected frequency of each size in the diet (based on abundance sampley from the observed frequency of each size in the diet. Dotted zero line separates sizes which were selected more frequently than expected (above the line) from those selected less frequently than expected (below the line). Note that the 3 points at the far left represent limpets 10,11 , and $12 \mathrm{~mm}$ in shell length 
When the difference between observed and expected diet frequency for each size is plotted as a function of the percent of that size found inhabiting deep home depressions, we find that sizes which show a greater than $50 \%$ incidence of deep home depression occupation (large limpets) are relatively neglected, sizes which show 20 to $40 \%$ deep home depression occupation (13 to $17 \mathrm{~mm}$ limpets) are preferred, and sizes which lack home depression (10 to $12 \mathrm{~mm}$ limpets) are taken approximately in proportion to their abundance (Fig. 7C). The sizes which produce the 3 left-most points on this graph are the smallest limpets (10 to $12 \mathrm{~mm}$ in length). Thus, though they predominantly lack home depressions and might therefore be expected to be desirable, they are near the lower limit of sizes acceptable to oystercatchers (Fig. 5) and are probably avoided on the basis of small size alone.

\section{DISCUSSION}

The results of this study bring a different perspective to the observations and speculations made by Haven (1971) concerning the spatial separation of 'Collisella' scabra and Lottia digitalis according to angle of substratum. Around Pacific Grove, we have found that $L$. digitalis (particularly those larger than $15 \mathrm{~mm}$ shell length) are most abundant on vertical rock surfaces out of reach of oystercatchers and are often actually outnumbered by 'C.' scabra on vertical surfaces accessible to these birds. Close examination of Haven's (1971) figures reveals the same pattern. Two of his figures (2B at Hopkins Marine Station, and 3L at Point Pinos) portray vertical rocks with horizontal surfaces at the base, and both show a notable scarcity of $L$. digitalis between 0 and $40 \mathrm{~cm}$ above the base. Our data for Pacific Grove, as well as our casual observations at other locations on the central California coast (e. g. Big Creek on the Big Sur coast south of Monterey, and Pebble Beach on the Monterey Peninsula) lead us to believe that this is a general phenomenon in areas where oystercatchers are present.

Because oystercatchers generally do not eat limpets smaller than about $10 \mathrm{~mm}$ in shell length, small limpets of all species, including Lottia digitalis, should be relatively free to inhabit areas accessible to oystercatchers. Indeed, as Haven (1971) notes, small $L$. digitalis are quite common on some horizontal surfaces, particularly those bearing some cover by acorn barnacles Balanus glandula. Our observation that $L$. digitalis living in reach of oystercatchers on vertical surfaces tend to be smaller than those out of reach (Fig. 3), and that the L. digitalis captured in the immediate vicinity are relatively large, supports the proposal that oystercatchers remove any larger individuals in reach. Limpets in reach which grow much larger than $10 \mathrm{~mm}$ are likely to be captured by oystercatchers (Fig. 3). The upward migratory behavior of L. digitalis (Frank 1965, Breen 1972) makes sense in this light. In areas where oystercatchers are present (historically, throughout the range of L. digitalis), the upward movement of small $L$. digitalis on vertical surfaces as they grow is clearly adaptive. Failure to do so may leave them at risk when they attain a size acceptable to the birds. Most other limpet species of California also migrate upward from relatively low intertidal settling areas, probably for a variety of reasons (Estes \& Lindberg in press). This tendency appears to be particularly important for $L$. digitalis in its high intertidal habitat, where hiding places (such as provided by foliose algae in lower zones) are scarce and the only certain refuge from bird predation is inaccessibility.

The distribution we have documented for Lottia digitalis and 'Collisella' scabra correlates well with the observation that oystercatchers neglect 'C.' scabra and prefer other limpets, such as L. digitalis. Our results do not explain why 'C.' scabra is less abundant on vertical surfaces where $L$. digitalis is common. Manipulations testing competition for food between these 2 species (Haven 1973) indicate that in mixed populations ' $C$.' scabra displays a more pronounced reduction in growth rate and maximum size than does L. digitalis. Haven also found a depletion of the diatom film, the primary food for these limpets, in his study plots containing both species (though this results is confounded by higher total limpet density in his mixed-species plots). Haven's inclusion cages prevented 'C.' scabra from escaping the presence of $L$. digitalis, but perhaps under natural conditions ' $C$.' scabra is more likely to leave areas inhabited by a dense population of $L$. digitalis. Underwood (1976) demonstrated a behavior pattern similar to this for the limpet Cellana tramoserica, which tends to home precisely as long as food is relatively abundant, but adopts a roving behavior pattern when food supplies are reduced. The effects of food supply on homing by 'Collisella' scabra have not been studied, but ' $C$.' scabra could respond to low food levels in area where $L$. digitalis are common by emigrating to adjacent regions with fewer $L$. digitalis and more food, and establishing home sites there.

Our tenacity measurements suggest that improved tenacity renders 'Collisella' scabra less desirable to oystercatchers than other limpets. It is interesting that, although 'C.' scabra without depressions on sandstone have lower tenacities than those with depressions, they are nevertheless significantly more tenacious than Lottia digitalis in the same area. Fit to home sites can explain the difference in tenacity between different ' $C$.' scabra on sandstone, and can enhance the difference in tenacity which is evidently already present between 'C.' scabra and L. digitalis. 
The superior resistance of 'Collisella' scabra to shear forces offers some protection from oystercatcher predation, but it clearly does not impart immunity (see Table 1) and oystercatchers can probably reduce 'C.' scabra numbers substantially if other preferred limpets become extremely scarce. At Pacific Grove, where the abundance of oystercatchers is about 1 pair per $3 \mathrm{~km}$ of coast for most of the year, limpets other than 'C.' scabra can be found in small numbers in most areas where the birds forage (with the possible exception of the immediate vicinity of nest sites), and 'C.' scabra are abundant. The situation is different in areas with very high densities of oystercatchers, such as Ano Nuevo Island. At Ano Nuevo, which has up to 4 pairs of oystercatchers per $\mathrm{km}$ of coastline, virtually all limpets, including ' $C$.' scabra, are scarce on rock surface accessible to birds (Lindberg pers. comm.); apparently birds have removed all limpets, including ' $C$.' scabra, from accessible areas. Thus, it is possible that the intensity of the predation may ultimately affect how selective the oystercatchers can afford to be, consistent with many theories of foraging behavior (e.g. Emlen 1966, MacArthur \& Pianka 1966, Krebs 1980). Consequently, the advantage conferred upon 'C.' scabra by homing behavior is contingent on the presence of at least small numbers of other more desirable prey species. In the absence of such alternative prey, oystercatchers evidently remove 'C.' scabra in spite of their occupation of home sites.

The reduction of predation by oystercatchers is probably not the sole function of homing by Collisella' scabra; homing may be adaptive for other reasons as well. In addition to the advantages summarized by Kunz \& Connor (1986), it may also be important in maintaining optimal dispersal of the population throughout the environment (e.g. Underwood 1976), and in resisting wave forces. In addition, Wright (unpubl., described on p. 348 in Branch 1981) has shown that ' $C$.' scabra in home depressions can successfully resist the shoving forces generated by territorial owl limpets Lottia gigantea. It is not surprising that such a complex behavior as homing would have evolved in response to multiple selective pressures.

Quite a few 'Collisella' scabra living on sandstone at Stillwater Cove lacked home depressions entirely (Fig. 7A). Oystercatchers foraging there took mostly 'C.' scabra of sizes less likely to have deep home depressions (limpets 13 to $17 \mathrm{~mm}$ in length), neglecting the larger limpets (18 $\mathrm{mm}$ or more in length), most of which inhabited deep home depressions. This relative neglect of the larger ' $C$.' scabra cannot be explained by there being a refuge in large size; oystercatchers studied by Hartwick (1978) showed a striking preference for limpets greater than $20 \mathrm{~mm}$ in length compared with those 10 to $20 \mathrm{~mm}$ in length. It is much more likely that the Stillwater Cove birds neglected larger 'C.' scabra because those limpets tended to possess deep home depressions. This could impose strong selection favoring the homing behavior of ' $C$.' scabra by eliminating those which do not home rigorously and do not possess well-formed depressions by the time they reach a size acceptable to oystercatchers.

Why so many 'Collisella' scabra should fail to produce well-defined depressions on sandstone is not clear. Perhaps some portions of the rock resist the etching process more than others (see Lindberg \& Dwyer 1983 for a description of this process). In any case, it takes a long time to produce a deep depression (one limpet which homed on a piece of sandstone in our lab for 3 mo had formed only a very slight impression in the rock surface at the end of this period). If some limpets have a tendency to adopt new home sites now and then, as some data indicates they do (F. Sommer pers. comm.), they may never develop a significant depression on sandstone.

Finally, we emphasize that we have not demonstrated a causal link between oystercatcher predation and the spatial separation of 'Collisella' scabra and Lottia digitalis. Experiments manipulating birds' accessibility to limpets on vertical rocks, e.g. by the use of shelves for the birds to walk on or bird exclusion cages, are critical in this regard. In addition, although we have shown that ' $C$.' scabra has superior resistance to shear forces due to its fit to a home depression or home site, again we have only shown a correlation between this fact and oystercatchers' tendency to neglect ' $C$.' scabra. However, oystercatcher predation appears to be a better explanation of differences in limpet distribution among different microhabitats than causal hypotheses related to interspecific competition alone, or to physical factors related to absolute and biological tidal height.

Acknowledgements. We thank D. P. Abbott, A. Baldridge, C. Baxter, and $D$. Lindberg for valuable input during the development of this research; C. Baxter, S. Gaines, D. Lindberg, R. Paine, and $T$. Wootton for comments on the manuscript; and F. Sommer for assistance in the field and with preparation of figures. Financial support for this work came in part from NSF Grant OCE-8314591 to M. Denny.

\section{LITERATURE CITED}

Branch, G. M. (1981). The biology of limpets: physical factors, energy flow, and ecological interactions. Oceanogr. mar. Biol. A. Rev. 19: 235-380

Brant, D. (1950). A quantitative study of the homing behavior of the limpet Acmaea scabra. Student report, Department of Zoology, University of California, Berkeley

Breen, P. A. (1971). Homing behavior and population regulation in the limpet Acmaea (Collisella) digitalis. Veliger 14: 177-183 
Breen, P. A. (1972). Seasonal migration and population regulation in the limpet Acmaea (Collisella) digitalis. Veliger 15: 133-141

Edwards, D. C., Conover, D. O., Sutter, F. (1982). Mobile predators and the structure of marine intertidal communities. Ecology 63: 1352-1362

Emlen, J. M. (1966). The role of time and energy in food preference. Am. Nat. 100: 611-617

Estes, J. A., Lindberg, D. R. (in press). Multi-causal disturbances and the non-equilibrium structure of a rocky intertidal community at San Nicolas Island, California. In: Hochberg F. I. (ed.) California Islands; Proceedings of a Multidisciplinary Symposium

Frank, P. W. (1965). The biodemography of an intertidal snail population. Ecology 46: 831-844

Frank, P. W. (1982). Effects of winter feeding on limpets by Black Oystercatchers, Haematopus bachmani. Ecology 63 $1352-1362$

Galbraith, R. T. (1965). Homing behavior in the limpets Acmaea digitalis and Lottia gigantea. Am. Midl. Nat. 74 $245-246$

Hartwick, E. B. (1976). Foraging strategy of the Black Oystercatcher (Haematopus bachmani Audubon). Can. J. Zool. 54: $142-155$

Hartwick, E. B. (1978). Some observations of foraging by Black Oystercatchers (Haematopus Bachmani Audubon). Syesis 11: $55-60$

Hartwick, E. B. (1981). Size gradients and shell polymorphism in limpets with consideration of the role of predation Veliger 23: 254-264

Haven, S. B. (1971). Niche differences in the intertidal limpets Acmaea scabra and Acmaea digitalis (Gastropoda) in central California. Veliger 13: 231-248

Haven, S. B. (1973). Competition for food between the intertidal gastropods Acmaea scabra and Acmaea digitalis. Ecology 54: 143-151

Hewatt, W. G. (1940). Observations on the homing limpet Acmaea scabra Gould. Am. Midl. Nat. 24: 205-208

Hockey, P. A. R., Cooper, J., Duffy, D. C. (1983). The roles of

This article was submitted to the editor coastal marine birds in the functioning of marine ecosystems in Southern Africa. S. Afr. J. Sci. 79: 130-134

Krebs, J. R. (1980). Optimal foraging, predation risk and territory defense. Ardea 68: 83-90

Kunz, C., Connor, V M. (1986). Roles of the home scar of Collisella scabra (Gould). Veliger 29: 25-30

Lindberg, D. R. (1986). Name changes in the 'Acmaeidae' Veliger 29: 142-148

Lindberg, D. R., Dwyer, K. B. (1983). The topography, formation and role of the home depression of Collisella scabra (Gould). Veliger 25: 229-234

Lindberg, D. R., Warheit, K. I., Estes, J. A. (1987). Prey preference and seasonal predation by oystercatchers on limpets at San Nicholas Island, California, USA. Mar. Ecol. Prog. Ser. 39: 105-113

MacArthur, R. A., Pianka, E. R. (1966). On optimal use of a patchy environment. Am. Nat. 100: 603-609

Mackay, D. A., Underwood, A. J. (1977). Experimental studies on homing in the intertidal patellid limpet Cellana tramoserica (Sowerby). Oecologia (Berl.) 30: 215-238

Marsh, C. D. (1986). Rocky intertidal community organization the impact of avian predators on mussel recruitment. Ecology $67: 771-786$

Marsh . C. D. (1987). Impact of avian predators on high intertidal limpet populations. J. exp. mar. Biol. Ecol. 104: 185-201

Underwood, A. J. (1976). Nearest-neighbour analyses of spatial dispersion of intertidal prosobranch gastropods within two substrata. Oecologia (Berl.) 26: 257-266

Villee, C. A., Groody, T. C. (1940). The behavior of limpets with reference to their homing instinct. Am. Midl. Nat. 24: 190-204

Wells, R. A. (1980). Activity pattern as a mechanism of predator avoidance in two species of Acmaeid limpet. J. exp. mar. Biol. Ecol. 48: 151-168

Wolcott, T G. (1973). Physiology, ecology and intertidal zonation in limpets (Acmaea): a critical look at 'limiting factors'. Biol. Bull. mar. biol. Lab., Woods Hole 145: 389-422

Zar, J. H. (1984). Biostatistical analysis (2nd edn). PrenticeHall, Inglewood Cliffs

Manuscript first received: July 4, 1988

Revised version accepted: January 20, 1989 